\section{Commentary: Modeling of dissection physiology to predict remodeling after thoracic endovascular aortic repair?}

\author{
Christoph A. Nienaber, MD, PhD, and \\ Xun Yuan, MBBS, MMED
}

The Beijing Institute of Technology in close cooperation with the Chinese PLA General Hospital and the Anzhen Hospital of the Capital University in Beijing made a great effort to create a useful clinical prediction tool to forecast the individual functional improvement by thoracic endovascular aortic repair (TEVAR) in the setting of type B dissection merely on the basis of computed tomography-derived image information. ${ }^{1}$ They developed a concept of pressure balance location, which is essentially a new parameter to describe the point of equal pressure between true and false lumen along the dissection. The more this so-called balance position of equal pressure is shifted distally by virtue of an endovascular stent graft the better. The assumption is that the subsequent aortic remodeling process will be better, too. They measure this process by use of posttreatment volumetric changes of the true and the false lumen over time. The balance position is essentially a zero luminal pressure differential derived from computed pressures in both the true and the false lumen separated by the dissection lamella and calculated from Doppler ultrasound velocimetry and the use of the Navier-Stokes equation with some reasonable assumptions (eg, that blood is a Newtonian fluid). Moreover, those pressures in the true and the false lumen were not measured invasively and directly but calculated using a mathematical model from fluid dynamics. Hence, a large proximal communication means the proximal location of the balance position and little chance to remodel. With endovascular treatment, the communication

\footnotetext{
From the Cardiology and Aortic Centre, Royal Brompton and Harefield Hospital NHS Foundation Trust, London, United Kingdom, and Faculty of Medicine, Department of Cardiology, National Heart and Lung Institute, Imperial College London, London, United Kingdom.

Disclosure: Authors have nothing to disclose with regard to commercial support.

Received for publication Feb 24, 2020; accepted for publication Feb 24, 2020; available ahead of print March 12, 2020.

Address for reprints: Christoph A. Nienaber, MD, PhD, Royal Brompton and Harefield Hospital NHS Foundation Trust, Sydney Street, London SW3 6NP United Kingdom (E-mail: c.nienaber@rbht.nhs.uk).

J Thorac Cardiovasc Surg 2021;162:e179-80 0022-5223/ $\$ 36.00$

Copyright (c) 2020 Published by Elsevier Inc. on behalf of The American Association for Thoracic Surgery

https://doi.org/10.1016/j.jtcvs.2020.02.107
}

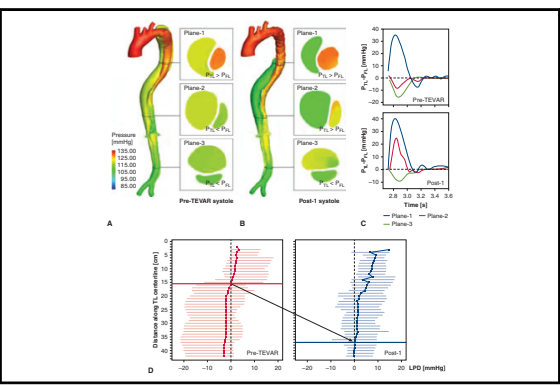

FL pressure decreasing post-TEVAR thus moving first (pressure) balance point distally.

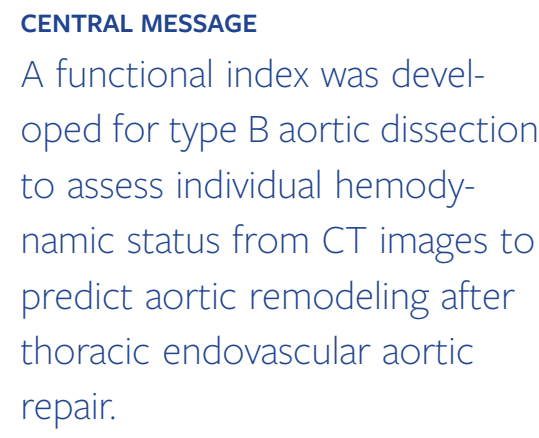

would be sealed, the balance position would shift distally and possibly beyond the dissected segment of the aorta, resulting in functional improvement by TEVAR. This observation indeed makes sense because a false lumen, when sealed off from pressure and flow has a chance to remodel the entire aorta. Thus, the concept of pressure balance is intriguing because it uses an independent hemodynamic implication; that is, pressure in the false lumen. From previous landmark studies ${ }^{2}$ we have learned that obstructed distal outflow from the false lumen and elevated diastolic and mean pressure in the false lumen is typical in the setting of partial false lumen thrombosis, which is characteristic of a subgroup of type B dissection with the worse outcomes. An intervention with TEVAR would neutralize pressure in the false lumen or shift the balance point at least distally with the expectation of good remodeling and outcome. Various previously published outcome studies in type B dissection have confirmed that induced remodeling leads to better long-term outcome. ${ }^{3-5}$ Finally, complete induced thrombosis and subsequent remodeling are established correlates of favorable long-term outcome in patients with any aortic dissection. So, the concept introduced by the authors appears founded on solid evidence and backed by independent clinical research. Moreover, this new prediction tool is complementary to the Stanford risk calculator that enables an aortic team (or the interested community in general) to predict the individual risk of a given patient based 
on anatomic features identified on the index or diagnostic computed tomography angiogram. ${ }^{6}$ Thus, the prediction tool helps to identify patients at future risk for aneurysmal degeneration even when considered uncomplicated on clinical grounds and symptoms. Finally, this tool is particularly useful in a setting of asymptomatic, initially uncomplicated patients with type B dissection to herald successful remodeling based on shifting the pressure balance position far distally, marking the road to success in any intervention to aortic dissection.

On aggregate, the concept and the tool introduced here is based on 51 patients who were analyzed retrospectively with a follow-up of 1 year and looks promising. However, to gain wide-spread acceptance, some sort of prospective validation needs to be gathered in a follow-up study.

\section{References}

1. Xu H, Xiong J, Han X, Mei Y, Shi Y, Wang D, et al. Computed tomography-based hemodynamic index for aortic dissection. J Thorac Cardiovasc Surg. 2021;162:e165-76.

2. Tsai TT, Evangelista A, Nienaber CA, Myrmel T, Meinhardt G, Cooper JV, et al. Partial thrombosis of the false lumen in patients with acute type B aortic dissection. N Engl J Med. 2007;357:349-59.

3. Fanelli F, Cannavale A, O'Sullivan GJ, Gazzetti M, Cirelli C, Lucatelli P, et al. Endovascular repair of acute and chronic aortic type B dissections: main factors affecting aortic remodeling and clinical outcome. JACC Cardiovasc Interv. 2016;9:183-91.

4. Nienaber CA, Kische S, Rousseau H, Eggebrecht H, Rehders TC, Kundt G, et al. Endovascular repair of type B aortic dissection: long-term results of the randomized investigation of stent grafts in aortic dissection trial. Circ Cardiovasc Interv. 2013;6:407-16.

5. Mitsis A, Yuan X, Cambronero-Cortinas E, Nienaber CA. New developments in the treatment of type B aortic dissection. Ital J Vasc Endovasc Surg. 2017;24:118-26.

6. Sailer AM, van Kuijk SM, Nelemans PJ, Chin AS, Kino A, Huininga M, et al. Computed tomography imaging features in acute uncomplicated stanford typeB aortic dissection predict late adverse events. Circ Cardiovasc Imaging. 2017;10.
See Article page e165.

\section{Commentary: Computed tomography-based hemodynamic index for aortic dissection: Ciceronian or say what?}

\begin{abstract}
Alan M. Speir, MD
Marcus Tullius Cicero (January 3, 106 BC-December 7, 43 $\mathrm{BC}$ ) was a noted Roman statesman, philosopher, and attorney, who is considered among Rome's greatest orators and prose stylists. ${ }^{1,2}$ Many of us are most familiar with his writings, albeit remotely, from arduous translations during the third-year Latin curriculum in high school or college. In publications that are particularly learned with a high degree of scholarship, such eloquence may be referred to as Ciceronian. This educated style stands in stark contrast to today's common communication through social media using Twitter, text messaging, Snapchat, and Instagram. All of
\end{abstract}

From the Department of Cardiac Surgery, Inova and Vascular Institute, Falls Church, Va.

Disclosure: Author has nothing to disclose with regard to commercial support.

Received for publication Feb 21, 2020; accepted for publication Feb 21, 2020; available ahead of print March 13, 2020.

Address for reprints: Alan M. Speir, MD, Department of Cardiac Surgery, Inova and Vascular Institute, 3300 Gallows Rd, Falls Church, VA 22042 (E-mail: alan.speir@ inova.org).

J Thorac Cardiovasc Surg 2021;162:e180-1 $0022-5223 / \$ 36.00$

Copyright $₫ 2020$ Published by Elsevier Inc. on behalf of The American Association for Thoracic Surgery

https://doi.org/10.1016/j.jtcvs.2020.02.103
Check for updates

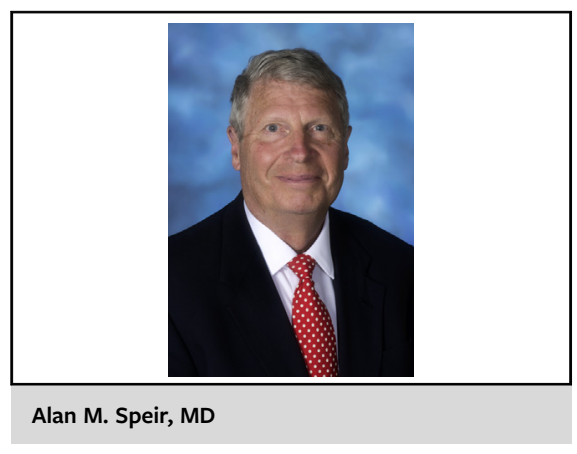

CENTRAL MESSAGE

Innovative imaging and analytic models, although challenging to interpret, may still be described in Ciceronian style.

these options focus on what is said, rather than how it is stated; hardly Ciceronian.

The recent article by Chen and colleagues ${ }^{3}$ can be described as Ciceronian. Through morphological assessments of complex 3-dimensional computed tomography images of aortas with type-B dissection, computational hemodynamic parameters and structural analyses of members of their patient series are elegantly presented. Mathematical 